Published in Gait \& Posture, 2020, vol. 82, pp. 233 - 241, which should be

cited to refer to this work. https://doi.org/10.1016/j.gaitpost.2020.09.014

\title{
Effects of the use of mobile phone on postural and locomotor tasks: a
}

\section{scoping review}

\author{
Anne-Violette Bruyneel, PhD, Pt *, Noémie Duclos, PhD, Pt ** \\ * Professeur (assistant) Geneva School of Health Sciences, HES-SO University of Applied Sciences \\ and Arts Western Switzerland \\ ** Professeur (assistant), Bordeaux Population Health Research Center, INSERM U1219, University \\ of Bordeaux, F-33000, Bordeaux, France; IUSR, Collège Sciences de la santé, University of \\ Bordeaux, F-33000, Bordeaux, France.
}

Corresponding author :

Anne-Violette Bruyneel

Rue des Caroubiers 25

CH- 1227 Carouge

Suisse

Anne-violette.bruyneel@hesge.ch

Orcid number: 0000-0003-4764-9336 


\title{
Effects of the use of mobile phone on postural and locomotor tasks: a
}

\section{scoping review}

\begin{abstract}
Background: Using a mobile phone while performing a postural and locomotor tasks is a common, daily situation. Conversing or sending messages (SMS) while walking account for a significant share of accidental injuries. Therefore, understanding the consequences of using a mobile phone on balance and walking is important, all the more so when these postural and locomotor tasks are aggravated by a disease.
\end{abstract}

Research question: Our objective was to conduct a scoping review on the influence of a dual-task situation - generated by the use of mobile phones - on users' postural and/or locomotor tasks.

Methods: The literature search was conducted in English on PubMed/Medline and CINHAL databases, using keywords associated with postural and locomotor tasks and with the use of mobile phones. Study location, population, number of subjects, experimental design, types of phone use, evaluated postural-locomotor tasks and expected effects were then analyzed.

Results and significance: 46 studies were included in this work, 24 of which came from North America. All studies compared postural and locomotor tasks with and without the use of a smartphone. Ten studies also compared at least 2 groups with different characteristics. Only 4 studies included pathological subjects. Various modalities were tested, and most studies focused on walking. Results show that the use of smartphones slows down movement and induces a systematic imbalance, except when listening to music. The dual task of "using the smartphone during a postural or locomotor tasks" induces systematic disturbances of balance and movement, which must be taken into account in the rehabilitation approach. Future studies will have to extend the knowledge regarding pathological situations. 


\section{Key words:}

Smartphone - balance - gait - dual task - ecological setting

\section{Highlights (3 to 5):}

- Conversing or sending messages while walking is often involved in accidental injuries

- Forty-six studies were included in this work

- They compared postural and locomotor tasks with and without the use of a smartphone

- Only 4 studies included pathological subjects

- The use of smartphones slows down movement and induces a systematic imbalance 


\section{EFFECTS OF THE USE OF MOBILE PHONE ON POSTURAL}

\section{AND LOCOMOTOR TASKS: A SCOPING REVIEW}

\section{Introduction}

In $2016,77 \%$ of Americans owned a mobile phone, and this rate rose to $92 \%$ for the $18-29$ year-olds [1]. Using of mobile phones during postural and locomotor tasks (e.g. balancing, walking) is a daily situation for most individuals at all stages of life and for a variety of environmental and health conditions [2]. Mobile phones are increasingly used in clinical practice by therapists thanks to applications that are being developed either to measure physiological parameters (e.g. motion range, balance) [3], or to improve the follow-up of individuals (e.g. self-exercise at home, questionnaires) [4]. While many studies have been conducted on these applications, studies on the use of mobile phones during postural and locomotor tasks and the reciprocal interactions are more scarce. Considering the preponderance of these tasks in our daily lives, it is therefore essential to understand the influence of mobile phone use on postural-locomotor tasks, especially for people with motor and/or cognitive deficits that diminish their balance and motor skills during dual tasks [5].

Five to $30 \%$ of walking-related falls and accidents are directly attributable to the use of a mobile phone $[1,6]$. People under 30 - due to their frequency of use - and over 60 are more exposed to risks, particularly when writing a text message [7]. Mobile phone use appears to induce cognitive distraction, reduced visual attention to the environment and impaired musculoskeletal biomechanics through decreasing arm and head mobility - which may be the main factors of risk [8]. However, one study also showed altered walking behavior when crossing a street [9]. Therefore, the use of a mobile phone seems to induce multiple consequences that may explain functional disturbances and associated risks. Nevertheless, the consequences of mobile phone use on the functionality of individuals are still little known. As a result, they are little taken into account in rehabilitation, even 
though patients under treatment very often use their phone - a crucial social component of their lives - and given that rehabilitation must be a dynamic process that adapts to changing lifestyles.

A scoping review is an alternative to a systematic review. It is used when the main objective is to determine the scope of available studies in order to have an overview of a topic [10]. This methodological choice is appropriate when the evidence is still emerging and does not allow for a systematic review to be conducted because the number of studies with similar methodologies on the same issue is too small. Scoping reviews differ methodologically from systematic reviews in that the authors do not evaluate article quality; it also differs from narrative reviews by its clearly-defined method [11]. Since studying the impact of mobile phone use on postural and locomotor tasks is a recent topic, and since the tasks tested can be varied (balance and walking), a scoping review is appropriate to identify the types of available evidence, to examine how research is conducted in this fields, and to identify knowledge gaps [10]. Moreover, the extremely frequent use of a mobile phone in conjunction with daily activities makes understanding this dual task relevant for patient rehabilitation.

Our objective was to conduct a scoping review on the influence of a dual task situation generated by the use of mobile phones - on users' postural and locomotor tasks.

\section{Methods}

The scoping review methodology followed the Joanna Briggs Institute (JBI)'s recommendations in 5 steps [12].

\section{Step 1: Identifying the Research Question}

The scoping review's question develops itself as the research proceeds and guides the inclusion and exclusion criteria for the selected studies. 
The original intention behind this review was to comprehensively review and map the evidence on

the effects of mobile phone use in conjunction with a postural and locomotor tasks.

Following our initial research, various sub-questions were identified:

- What are the studies' target populations?

- Which types of phone use were investigated?

- Which types of postural and locomotor tasks were investigated?

- What is the environment in which the tests were conducted?

\section{Step 2: Identifying relevant studies}

\section{Eligibility criteria}

\section{Criteria for inclusion}

The selected articles had to be written in English or French and published in the last ten years (20102019). This time frame seems appropriate considering the evolution of mobile phone technology and use. The studies' main target was the influence of mobile phone use on the spatio-temporal parameters of postural and/or locomotor tasks. Only experimental studies were considered for this work. This review included studies with different levels of evidence in order to answer the question in a broad manner. The subjects targeted in the studies had to be adults (age $>18$ years) with no upper age limit. We only included studies targeting quantitative measures. All studies were included regardless of the phone models (e.g. brands, versions), interfaces (e.g. keys, touch screen) or operating systems (e.g. Apple, Android).

\section{Criteria for exclusion}

All articles which did not include a separated analysis of the task's conditions (a mobile phone used in conjunction with such postural and/or locomotor task) were excluded in order to correctly answer the research question. 
Articles that offered only visual exploration and an analysis of urban safety strategies (for drivers and

\section{Step 3: article selection}

\section{Databases and key words}

A literature search was conducted by two independent evaluateurs (ND and AVB) between January 15 and February 15, 2020. The search strategy followed the steps of the PRISMA flow chart. The databases searched were PubMed / Medline and CINHAL, using the additional filters "ten years", "clinical trial" and "human". Articles were then searched without the "clinical trial" filter - as some articles meeting the inclusion criteria did not appear when this filter was on. Articles in English were initially searched using the keywords: "phone AND balance". After this initial search, the keyword "phone" was combined with the Boolean operators "AND" and "OR" with the keywords "texting", "calling", "gait", "standing", "posture". Duplicate articles were then deleted.

Titles and abstracts were read to assess whether the content appeared to meet the inclusion criteria. For $30 \%$ of the randomly-selected titles, selection following the reading of the abstracts was conducted by the two evaluators. In case of disagreement, a discussion was held to find a consensus and, if necessary, a third person was asked to decide on the inclusion of the article.

Access to the full text was then checked before considering the articles' final inclusion.

Then, as recommended by $\mathrm{JBI}$, a second selection was made from the bibliographic references of the articles found during the first selection phase. 


\section{Step 4: Data Mapping and Synthesis of Results}

The details of the research process and results obtained were represented in the form of a PRISMA flow chart. The distribution over the years of the number of published and selected studies was summarized in a chart. The complete reading of the text allowed, for each article, to extract: information regarding authors, publication year, study location, objectives, experimental design, the participants' characteristics, the studied phone use types, the postural and locomotor tasks tested and the main results obtained. In order to harmonize the two evaluators' methods, a standardized data extraction protocol was used.

\section{Step 5: Studies' Implications for Clinical Practice and Research}

The methodological approach for this scoping review allowed gathering existing data on the impact of mobile phone use on postural and locomotor tasks.

The report was written in order to:

- Propose a distribution of studies by publication period and country of origin;

- Highlight the target populations of studies on the dual task "mobile phone - posturaldynamic task";

- Produce a synthesis - in the form of a table - according to the phone use types and postural and locomotor tasks tested and the results obtained, allowing to identify the impact of mobile phone use on the subjects' behavior.

\section{Results}

\section{Article selection}

The PRISMA flow chart (Figure 1) shows the results for each selection stage. The literature search identified a total of 2,940 articles on PubMed/Medline, CINHAL and in other articles' references. After selection, 46 articles were included in the synthesis. 
Please insert Figure 1.

\section{Study characteristics}

\section{Year of publication}

The total number of studies published on PubMed/Medline responding to the keywords used has increased steadily since 2010 (Figure 2). For the articles included, the two most represented years were 2015 (12 articles) and 2018 (9 articles), while no article published in 2010 met our criteria.

Please insert Figure 2.

\section{Geographic location}

Half of the studies were carried out in North America (52\%), a quarter in Asia (26\%), and the others in Europe (16\%), Africa, South America and Australia-Oceania (table 1).

Please insert table 1.

\section{$\underline{\text { Design }}$}

All included studies were experimental, and systematically compared conditions (postural and locomotor tasks combined with the use of a mobile phone vs. tasks alone). Of these studies, $22 \%$ also compared sub-groups of different populations (table 1).

\section{$\underline{\text { Test environment }}$}

Three types of environments were used: laboratory testing (76\% of studies), ecological setting (20\%) and clinical setting (9\%) (Table 1). Three studies compared results between laboratory and ecological settings [13-15]. For one study, it was not possible to identify the environment [13]. 


\section{Studied populations}

Forty-five studies out of 46 investigated the effects of smartphone use on postural and locomotor tasks in healthy subjects; 6 studies included elderly subjects [14-19] and 4 studies included people with an illness: multiple sclerosis [20,21], fibromyalgia [22] or Parkinson's disease [23] (Table 1). In total, the healthy population amounted to 1,922 young adults, 127 middle-aged subjects (between 35 and 60 years old) and 88 elderly subjects (> 60 years old). In one study on 1,142 healthy subjects, age was not indicated [24]. The effects of phone use on postural and locomotor tasks were evaluated in 101 people with Parkinson's disease, 84 with multiple sclerosis and 18 with fibromyalgia.

\section{Type of phone use}

All studies were conducted using a smartphone. The types of phone use during postural and locomotor tasks were varied, including mainly texting (34 studies), calling (13 studies), listening to music (5 studies), web browsing (4 studies) and gaming (4 studies) (Figure 3 ).

Please insert Figure 3.

\section{Studied postural-locomotor tasks}

The influence of mobile phone use was studied in static (standing balance - 4 studies; and sitting balance - 1 study) and in dynamic conditions (Figure 4). For walking (analyzed in 41 studies), subjects were asked to either move on the floor (23 studies), walk on a treadmill (11 studies), walk over obstacles (6 studies), or walk on an inclined plane (1 study). In dynamic contexts, the following clinical tests were conducted (5 studies): the Timed Up and Go, the Stair Ambulation and the Star Excursion Balance tests.

Please insert Figure 4. 


\section{Key results}

Compared to the same postural-locomotor task without using a mobile phone, texting mainly induced a slowdown and increased instability when walking on the ground $[7,13-15,20,21,24-31]$, on a treadmill [7,32-35], with obstacles [36-42] and on an inclined plane (only when going downhill) [43].

No significant effect was observed on knee and ankle angles when walking on the ground [44], and 3 studies found no effect for texting while walking on a treadmill $[16,45,46]$ (Table 2$)$. While texting, a decrease in speed was also observed for the Timed Up and Go and Stair Ambulation [28] tests, in addition to a decrease in performance in the Star Excursion Balance test $[47,48]$. Moreover, standing balance was significantly more unstable compared to the control condition $[47,49]$.

Please insert table 2.

Decreased walking speed and increased instability were also observed under different walking conditions and for the Timed Up and Go test during phone calls $[18,19,24,26,29,31,33,38,50-$ 52], except for one study [53]. During the call, standing balance was significantly more unstable compared to the control condition $[18,22]$.

Dialing $[13,17,18]$, web browsing $[48,49,52-54]$, reading a text $[7,38,52]$, writing the test date [23], watching a movie [30], interacting with an application [36,50], playing games $[30,40,48,53]$ and taking "selfies" [52] systematically slowed down movements, increased instability and decreased test performance. On the other hand, listening to music either had no effect $[18,19]$ or increased the speed of movements $[18,31,33]$.

When the mobile phone was held to the ear while participants maintained prolonged sitting balance, there was a change in the head position [55]. 
For all conditions, the same characteristics were observed during the dual task, but the

disturbances were greater for elderly subjects [14-19], people with multiple sclerosis [20,21], fibromyalgia [22] or Parkinson's disease [23].

\section{Discussion}

The objective of this scoping review was to review studies on the effects of mobile phone use in conjunction with a postural and locomotor task. The main effects reported in the 46 studies included were consistent, with an observed instability in postural and locomotor tasks and a slowing down of dynamic tasks (including locomotor tasks) during mobile phone use.

The use of a mobile phone during a postural-locomotor task matches the dual task situation as defined in the review by Mclssaac et al. [56]. Indeed, dual tasks require the simultaneous performance of two interfering tasks. But each of these can be performed independently, measured in a distinct way, and meeting its own objectives. All types of use of a mobile phone generate visual, cognitive and fine motor activities that contribute to the modification of gait. These, are more complex dual tasks than those usually used in clinical practice [13]. In all included studies, the effects of the interference between the smartphone task and the postural-locomotor task were assessed using spatio-temporal parameters. In healthy young adults, during the dual task of texting while walking, test-retest reliability was good to excellent for the spatial-temporal parameters of walking, while it was poor for the evaluation of texting speed [57]. This supports the superiority of spatiotemporal parameters for assessing the effects of a dual task during walking [15]. This good metrological quality is interesting for rehabilitation clinicians who can use this dual-task test to implement exercises that are adapted and representative of daily activities - including using a smartphone while performing postural-dynamic tasks. 
The dual task paradigm is particularly relevant for use in clinical practice with people in

fragile situations, since a dual task that degrades motor performance may be associated with an increased risk of falls for the elderly [58] and for people with Parkinson's disease [59]. However, only 10 studies out of 46 have studied the effects of mobile phone use during a postural and/or locomotor task in elderly and pathological subjects. Yet, aging and the pathologies under consideration (Parkinson's disease, multiple sclerosis, fibromyalgia) are known to induce deficits in postural control, motor tasks and cognitive functions, which could increase the dual task's negative effects on the spatial and temporal parameters of the postural and locomotor task [60-63]. In accordance, articles that include group comparison were able to show that the adverse effects of mobile phone use on balance and locomotor performance were greater in these populations than in young and/or healthy people $[14,15,17-22]$. Motor and cognitive control skills therefore appear to be essential for managing a dual task, as more and more patients use their phone while walking. Therefore, future studies will need to further the knowledge on this daily dual task for people in fragile situations, and to evaluate the predictive aspect of these dual-task tests on the risk of falls during walking.

Regardless of the type of use, mobile phones involve vision, cognition and fine motor skills [2]. The level of mobilization of these resources depends on the task performed on the phone. Hence, a study on texting while walking has shown that this type of use involves - in order of importance - cognitive aspects, then visual aspects and finally motor aspects [13]. A review on personal safety showed that, compared to calling, texting further reduced visual exploration to the right and left before and during crossing intersections, which increased the rate of collisions and near-collisions [64]. In their literature review, Krasovsky et al. chose to focus on this type of mobile phone use because it involves active user interaction with the phone screen [2]. Nevertheless, our results show that the active interaction of the user with the screen has been studied more broadly, for uses other than texting - such as dialing, web browsing or using an application, playing games or taking a picture. Phone calls and listening to music - which are less interactive types of use - appear 
to have the least influence on subjects' ability to manage their postural-dynamic task $[18,33,51,53]$.

The control condition in the included studies was mainly the completion of the usual postural and locomotor tasks without the use of a smartphone. Nevertheless, Prupetkaew et al. proposed, as a control condition, a balance-and-walking task while holding the phone with one or both hands, without actually using it [14]. This proposition is interesting in order to dissociate the effect of the position induced by the use of the mobile phone, and the effect of the use itself on spatio-temporal parameters. No study has tested the dual task when using a navigation application, whereas this type of use is very frequently used while walking. Such an inquiry would be interesting, because holding the phone and interacting with the screen stiffens the upper limb swaying when walking and reduces the visual field, but it supports topographical orientation - which mobilizes particular cognitive resources and is less efficient in elderly people [65].

Different postural and locomotor tasks were considered. The use of a mobile phone (except for music) systematically induced a decrease in the speed of movement, and an increase in the instability and variability of the studied parameters. While movement slowdown can be considered as a precautionary compensatory strategy, the other aspects are unintentional and are direct consequences of the phone use during postural-locomotor tasks [66]. Static and dynamic equilibrium is less efficient when using a smartphone, except when listening to music [18]. Walking was the most frequently studied locomotor task - on the floor, on a treadmill, on an inclined floor or with obstacles. Some authors chose to have participants walk on the ground because they suspected a reduction in walking speed - which is harder to detect with a treadmill. However, the use of a treadmill allowed participants to walk for long periods of time, up to 10 minutes [32,35] and 30 minutes [33], which corresponds more to the daily duration of such a dual task. A more specific analysis of the effects observed depending on the walking surfaces used could be conducted, since walking on the ground and on a treadmill can be similar or different depending on the parameters considered $[67,68]$. Thus, some authors report a decrease in stride length [69] and step length $[70]$ in elderly people during treadmill walking compared to walking on the ground, which contributes to a 
faster pace. In addition, it seems that a dual task while walking on the ground is not performed in the

same way as when walking on a treadmill $[71,72]$. Indeed, young subjects seem to be able to prioritize the cognitive task when walking on a treadmill (better performance than walking on the ground), without gait being affected [71]. The results of this scoping review also seem to show that walking on the treadmill less emphasizes the effects of texting (3 studies with non-significant results) than walking on the ground (1 study with non-significant results, only on the knee and ankle kinematic parameters). One of the hypotheses put forward is that walking on a treadmill has a lower impact on cognitive ressources than walking on the ground [73]. The effects of phone use have also been studied while crossing obstacles when walking on the ground [38], walking on a treadmill with a virtual obstacle [41] and walking up and down stairs [28]. Considering the balance imperatives [74], the muscular strength [75], the impact on cognitive ressources [76] and the role of visual information [77] during these tasks, it is coherent for them to be particularly altered by the use of the mobile phone. The focus on these tasks in the studies reviewed illustrates the researchers' desire to propose experimental conditions that are close to people's everyday activities.

In the ecological setting, the review by Stravrinos et al. on safety while using mobile phones showed a systematic slowdown while walking, cycling and driving as well as a decrease in the type of phone use [66]. While the majority of studies were conducted under clinical conditions, three studies have compared results from the clinical and ecological settings $[14,15,25]$. Indoor environments had no significant effects on walking [14], but they tend to modify the task spontaneously prioritized by young adults [25]. When texting, walking outdoors increased the dual task's cost compared to an indoor environment, as well as age-related effects [15]. These observations suggest that clinicians should assess their patients' abilities in ecological environments, especially when dual tasking using a mobile phone in the same way that patients would in real life. Clinicians could set up the tests used in clinical practice - such as the "timed up and go test" - in a shopping mall or in a park. They could themselves talk to the patient, through text message or call - as experimenters in studies did -, directly observe the effects of using a phone on the person's performance, and identify new areas of 
care. This approach would be consistent with the World Health Organization's policy of bringing rehabilitation actions closer to the community and integrating them into a disability prevention strategy.

Certain limitations of this work must be considered. Explicit mention of the research environment was a missing element in several studies, forcing the reviewers to assume the exact location of the tests. Studies did not always report how familiar people were with a mobile phone, while some studies required minimal daily phone use for subjects to be included. In addition, we focused on the effects of mobile phone use on postural and locomotor tasks but chose not to consider the effects of postural-locomotor tasks on phone use. Spatio-temporal parameters have the advantage of being more reliable and it is these aspects that will be of primary interest to rehabilitation clinicians. However, the quality analysis of the two tasks may be interesting to consider, particularly in the case of cognitive disorders.

\section{Conclusion}

Results show that many studies have already considered the effects of mobile phone use on spatial and temporal parameters during postural and locomotor tasks. The types of mobile phone use and the tasks explored were varied, with a predominant interest in texting and walking. The studies aimed to select tasks that represent daily life, but the experiments most often took place in a controlled environment (a laboratory, a clinic) rather than a living environment (ecological setting). Similarly, the older persons are often presented as the most at-risk populations during these tasks, but they represent a small proportion of the populations studied. This scoping review supports different avenues of research in order to study more specifically the postural-dynamic impacts of mobile phone use, as well as for rehabilitation clinicians to tailor their interventions as closely as possible to the daily situations of individuals. 


\section{Figure legends:}

Figure 1: Flow chart Prisma

Figure 2: Number of publications per year on the PubMed database with the keyword "phone". The dotted line represents the number of articles published per year that have been included in this journal.

Figure 3: Percentage of studies that were published, by the type of phone use.

Figure 4: Number of published studies by type of postural-dynamic task.

\section{REFERENCES}

[1] C.S. Gary, C. Lakhiani, M.V. DeFazio, D.L. Masden, D.H. Song, Smartphone use during ambulation and pedestrian trauma: A public health concern, J Trauma Acute Care Surg. 85 (2018) 1092-1101. https://doi.org/10.1097/TA.0000000000002051.

[2] T. Krasovsky, P.L. Weiss, R. Kizony, A narrative review of texting as a visually-dependent cognitive-motor secondary task during locomotion, Gait Posture. 52 (2017) 354-362. https://doi.org/10.1016/j.gaitpost.2016.12.027.

[3] N. Shah, R. Aleong, I. So, Novel Use of a Smartphone to Measure Standing Balance, JMIR Rehabil Assist Technol. 3 (2016) e4. https://doi.org/10.2196/rehab.4511.

[4] B. Gialanella, L. Comini, A. Olivares, E. Gelmini, E. Ubertini, G. Grioni, Pain, disability and adherence to home exercises in patients with chronic neck pain: long term effects of phone surveillance. A randomized controlled study, Eur J Phys Rehabil Med. (2019). https://doi.org/10.23736/S1973-9087.19.05686-7.

[5] Y.-C. Liu, Y.-R. Yang, Y.-A. Tsai, R.-Y. Wang, Cognitive and motor dual task gait training improve dual task gait performance after stroke - A randomized controlled pilot trial, Sci Rep. 7 (2017) 4070. https://doi.org/10.1038/s41598-017-04165-y.

[6] J.L. Nasar, D. Troyer, Pedestrian injuries due to mobile phone use in public places, Accid Anal Prev. 57 (2013) 91-95. https://doi.org/10.1016/j.aap.2013.03.021. 
[7] S.M. Schabrun, W. van den Hoorn, A. Moorcroft, C. Greenland, P.W. Hodges, Texting and walking: strategies for postural control and implications for safety, PLoS ONE. 9 (2014) e84312. https://doi.org/10.1371/journal.pone.0084312.

[8] P.-C. Kao, C.I. Higginson, K. Seymour, M. Kamerdze, J.S. Higginson, Walking stability during cell phone use in healthy adults, Gait Posture. 41 (2015) 947-953.

https://doi.org/10.1016/j.gaitpost.2015.03.347.

[9] D. Stavrinos, K.W. Byington, D.C. Schwebel, Distracted walking: cell phones increase injury risk for college pedestrians, J Safety Res. 42 (2011) 101-107. https://doi.org/10.1016/j.jsr.2011.01.004.

[10] Z. Munn, M.D.J. Peters, C. Stern, C. Tufanaru, A. McArthur, E. Aromataris, Systematic review or scoping review? Guidance for authors when choosing between a systematic or scoping review approach, BMC Medical Research Methodology. 18 (2018) 143. https://doi.org/10.1186/s12874-018-0611-x.

[11] D. Levac, H. Colquhoun, K.K. O'Brien, Scoping studies: advancing the methodology, Implement Sci. 5 (2010) 69. https://doi.org/10.1186/1748-5908-5-69.

[12] Chapter 11: Scoping reviews - JBI Reviewer's Manual - JBI GLOBAL WIKI, (n.d.). https://wiki.joannabriggs.org/display/MANUAL/Chapter+11\%3A+Scoping+reviews (accessed March 17, 2020).

[13] Y. Tian, Y. Huang, J. He, K. Wei, What affects gait performance during walking while texting? A comparison of motor, visual and cognitive factors, Ergonomics. 61 (2018) 1507-1518. https://doi.org/10.1080/00140139.2018.1493153.

[14] P. Prupetkaew, V. Lugade, T. Kamnardsiri, P. Silsupadol, Cognitive and visual demands, but not gross motor demand, of concurrent smartphone use affect laboratory and free-living gait among young and older adults, Gait Posture. 68 (2019) 30-36. https://doi.org/10.1016/j.gaitpost.2018.11.003.

[15] T. Krasovsky, P.L. Weiss, R. Kizony, Older Adults Pay an Additional Cost When Texting and Walking: Effects of Age, Environment, and Use of Mixed Reality on Dual-Task Performance, Phys Ther. 98 (2018) 549-559. https://doi.org/10.1093/ptj/pzy047.

[16] P.-C. Kao, C.I. Higginson, K. Seymour, M. Kamerdze, J.S. Higginson, Walking Stability during Cell Phone Use in Healthy Adults, Gait Posture. 41 (2015) 947-953. https://doi.org/10.1016/j.gaitpost.2015.03.347.

[17] K.M. Seymour, C.I. Higginson, K.M. DeGoede, M.K. Bifano, R. Orr, J.S. Higginson, Cellular Telephone Dialing Influences Kinematic and Spatiotemporal Gait Parameters in Healthy Adults, J Mot Behav. 48 (2016) 535-541. https://doi.org/10.1080/00222895.2016.1152226.

[18] R. Laatar, H. Kachouri, R. Borji, H. Rebai, S. Sahli, The effect of cell phone use on postural balance and mobility in older compared to young adults, Physiol. Behav. 173 (2017) 293-297. https://doi.org/10.1016/j.physbeh.2017.02.031.

[19] M.B. Neider, J.G. Gaspar, J.S. McCarley, J.A. Crowell, H. Kaczmarski, A.F. Kramer, Walking and talking: dual-task effects on street crossing behavior in older adults, Psychol Aging. 26 (2011) 260-268. https://doi.org/10.1037/a0021566.

[20] B. Sirhan, L. Frid, A. Kalron, Is the dual-task cost of walking and texting unique in people with multiple sclerosis?, J Neural Transm (Vienna). 125 (2018) 1829-1835. https://doi.org/10.1007/s00702-018-1939-4.

[21] M. Pau, F. Corona, G. Pilloni, M. Porta, G. Coghe, E. Cocco, Texting while walking differently alters gait patterns in people with multiple sclerosis and healthy individuals, Mult Scler Relat Disord. 19 (2018) 129-133. https://doi.org/10.1016/j.msard.2017.11.021.

[22] S. Villafaina, N. Gusi, S. Rodriguez-Generelo, J. de D. Martin-Gallego, J.P. Fuentes-García, D. Collado-Mateo, Influence of a Cell-Phone Conversation on Balance Performance in Women with Fibromyalgia: A Cross-Sectional Descriptive Study, Biomed Res Int. 2019 (2019) 5132802. https://doi.org/10.1155/2019/5132802.

[23] C. Strouwen, E.A.L.M. Molenaar, S.H.J. Keus, L. Münks, E. Heremans, W. Vandenberghe, B.R. Bloem, A. Nieuwboer, Are factors related to dual-task performance in people with Parkinson's 
disease dependent on the type of dual task?, Parkinsonism Relat. Disord. 23 (2016) 23-30. https://doi.org/10.1016/j.parkreldis.2015.11.020.

[24] J.E. Barkley, A. Lepp, Cellular telephone use during free-living walking significantly reduces average walking speed, BMC Res Notes. 9 (2016) 195. https://doi.org/10.1186/s13104-0162001-y.

[25] P. Plummer, S. Apple, C. Dowd, E. Keith, Texting and walking: effect of environmental setting and task prioritization on dual-task interference in healthy young adults, Gait Posture. 41 (2015) 46-51. https://doi.org/10.1016/j.gaitpost.2014.08.007.

[26] E.M. Lamberg, L.M. Muratori, Cell phones change the way we walk, Gait Posture. 35 (2012) 688-690. https://doi.org/10.1016/j.gaitpost.2011.12.005.

[27] N.D. Parr, C.J. Hass, M.D. Tillman, Cellular phone texting impairs gait in able-bodied young adults, J Appl Biomech. 30 (2014) 685-688. https://doi.org/10.1123/jab.2014-0017.

[28] A.J. Strubhar, B. Rapp, D. Thomas, Changes in Gait and Texting Ability During Progressively Difficult Gait Tasks, Int J Exerc Sci. 10 (2017) 743-753.

[29] P. Crowley, P. Madeleine, N. Vuillerme, The effects of mobile phone use on walking: a dual task study, BMC Res Notes. 12 (2019) 352. https://doi.org/10.1186/s13104-019-4391-0.

[30] S. Haga, A. Sano, Y. Sekine, H. Sato, S. Yamaguchi, K. Masuda, Effects of using a Smart Phone on Pedestrians' Attention and Walking, Procedia Manufacturing. 3 (2015) 2574-2580. https://doi.org/10.1016/j.promfg.2015.07.564.

[31] L.L. Thompson, F.P. Rivara, R.C. Ayyagari, B.E. Ebel, Impact of social and technological distraction on pedestrian crossing behaviour: an observational study, Injury Prevention. 19 (2013) 232-237. https://doi.org/10.1136/injuryprev-2012-040601.

[32] J.R. Marone, P.B. Patel, C.P. Hurt, M.D. Grabiner, Frontal plane margin of stability is increased during texting while walking, Gait Posture. 40 (2014) 243-246. https://doi.org/10.1016/j.gaitpost.2014.04.188.

[33] M.J. Rebold, A. Lepp, G.J. Sanders, J.E. Barkley, The impact of cell phone use on the intensity and liking of a bout of treadmill exercise, PLoS ONE. 10 (2015) e0125029. https://doi.org/10.1371/journal.pone.0125029.

[34] J. Lim, A. Amado, L. Sheehan, R.E.A. Van Emmerik, Dual task interference during walking: The effects of texting on situational awareness and gait stability, Gait Posture. 42 (2015) 466-471. https://doi.org/10.1016/j.gaitpost.2015.07.060.

[35] M.D. Grabiner, J.R. Marone, M. Wyatt, P. Sessoms, K.R. Kaufman, Performance of an attentiondemanding task during treadmill walking shifts the noise qualities of step-to-step variation in step width, Gait Posture. 63 (2018) 154-158. https://doi.org/10.1016/j.gaitpost.2018.04.041.

[36] S. Licence, R. Smith, M.P. McGuigan, C.P. Earnest, Gait Pattern Alterations during Walking, Texting and Walking and Texting during Cognitively Distractive Tasks while Negotiating Common Pedestrian Obstacles, PLoS ONE. 10 (2015) e0133281. https://doi.org/10.1371/journal.pone.0133281.

[37] R. Hashish, M.E. Toney-Bolger, S.S. Sharpe, B.D. Lester, A. Mulliken, Texting during stair negotiation and implications for fall risk, Gait Posture. 58 (2017) 409-414. https://doi.org/10.1016/j.gaitpost.2017.09.004.

[38] M.A. Timmis, H. Bijl, K. Turner, I. Basevitch, M.J.D. Taylor, K.N. van Paridon, The impact of mobile phone use on where we look and how we walk when negotiating floor based obstacles, PLoS ONE. 12 (2017) e0179802. https://doi.org/10.1371/journal.pone.0179802.

[39] S.M. Lopresti-Goodman, A. Rivera, C. Dressel, Practicing Safe Text: the Impact of Texting on Walking Behavior, Applied Cognitive Psychology. 26 (2012) 644-648. https://doi.org/10.1002/acp.2846.

[40] J. Cha, H. Kim, J. Park, C. Song, Effects of mobile texting and gaming on gait with obstructions under different illumination levels, Physical Therapy Rehabilitation Science. 4 (2015) 32-37. https://doi.org/10.14474/ptrs.2015.4.1.32.

[41] P. Chopra, D.M. Castelli, J.B. Dingwell, Cognitively Demanding Object Negotiation While Walking and Texting, Sci Rep. 8 (2018) 17880. https://doi.org/10.1038/s41598-018-36230-5. 
[42] S.-H. Chen, O.-Y. Lo, T. Kay, L.-S. Chou, Concurrent phone texting alters crossing behavior and induces gait imbalance during obstacle crossing, Gait Posture. 62 (2018) 422-425. https://doi.org/10.1016/j.gaitpost.2018.04.004.

[43] G.Y. Kim, M.R. Han, H.G. Lee, Effect of Dual-task Rehabilitative Training on Cognitive and Motor Function of Stroke Patients, J Phys Ther Sci. 26 (2014) 1-6. https://doi.org/10.1589/jpts.26.1.

[44] V. Agostini, F. Lo Fermo, G. Massazza, M. Knaflitz, Does texting while walking really affect gait in young adults?, J Neuroeng Rehabil. 12 (2015) 86. https://doi.org/10.1186/s12984-015-0079-4.

[45] D.C. Hinton, Y.-Y. Cheng, C. Paquette, Everyday multitasking habits: University students seamlessly text and walk on a split-belt treadmill, Gait Posture. 59 (2018) 168-173. https://doi.org/10.1016/j.gaitpost.2017.10.011.

[46] J. Lim, S.H. Chang, J. Lee, K. Kim, Effects of smartphone texting on the visual perception and dynamic walking stability, J Exerc Rehabil. 13 (2017) 48-54. https://doi.org/10.12965/jer.1732920.460.

[47] N.R. Nurwulan, B.C. Jiang, H. Iridiastadi, Posture and Texting: Effect on Balance in Young Adults, PLoS One. 10 (2015). https://doi.org/10.1371/journal.pone.0134230.

[48] I.H. Hyong, The effects on dynamic balance of dual-tasking using smartphone functions, J Phys Ther Sci. 27 (2015) 527-529. https://doi.org/10.1589/jpts.27.527.

[49] S.-H. Cho, M.-H. Choi, B.-O. Goo, Effect of smart phone use on dynamic postural balance, J Phys Ther Sci. 26 (2014) 1013-1015. https://doi.org/10.1589/jpts.26.1013.

[50] S. Jeon, C. Kim, S. Song, G. Lee, Changes in gait pattern during multitask using smartphones, Work. 53 (2015) 241-247. https://doi.org/10.3233/WOR-152115.

[51] R.M. Magnani, G.C. Lehnen, F.B. Rodrigues, G.S. de Sá E Souza, A. de Oliveira Andrade, M.F. Vieira, Local dynamic stability and gait variability during attentional tasks in young adults, Gait Posture. 55 (2017) 105-108. https://doi.org/10.1016/j.gaitpost.2017.04.019.

[52] D. Niederer, A. Bumann, Y. Mühlhauser, M. Schmitt, K. Wess, T. Engeroff, J. Wilke, L. Vogt, W. Banzer, Specific smartphone usage and cognitive performance affect gait characteristics during free-living and treadmill walking, Gait Posture. 62 (2018) 415-421. https://doi.org/10.1016/j.gaitpost.2018.04.007.

[53] C. Caramia, I. Bernabucci, C. D'Anna, C. De Marchis, M. Schmid, Gait parameters are differently affected by concurrent smartphone-based activities with scaled levels of cognitive effort, PLoS ONE. 12 (2017) e0185825. https://doi.org/10.1371/journal.pone.0185825.

[54] H. Han, G. Shin, Head flexion angle when web-browsing and texting using a smartphone while walking, Appl Ergon. 81 (2019) 102884. https://doi.org/10.1016/j.apergo.2019.102884.

[55] Z.C. Thumser, J.S. Stahl, Handheld cellular phones restrict head movements and range of visual regard, Hum Mov Sci. 32 (2013) 1-8. https://doi.org/10.1016/j.humov.2012.03.002.

[56] T.L. Mclsaac, E.M. Lamberg, L.M. Muratori, Building a framework for a dual task taxonomy, Biomed Res Int. 2015 (2015) 591475. https://doi.org/10.1155/2015/591475.

[57] D. Hamacher, D. Hamacher, A. Törpel, M. Krowicki, F. Herold, L. Schega, The reliability of local dynamic stability in walking while texting and performing an arithmetical problem, Gait Posture. 44 (2016) 200-203. https://doi.org/10.1016/j.gaitpost.2015.12.021.

[58] S.W. Muir-Hunter, J.E. Wittwer, Dual-task testing to predict falls in community-dwelling older adults: a systematic review, Physiotherapy. 102 (2016) 29-40. https://doi.org/10.1016/j.physio.2015.04.011.

[59] V.E. Kelly, A.J. Eusterbrock, A. Shumway-Cook, A review of dual-task walking deficits in people with Parkinson's disease: motor and cognitive contributions, mechanisms, and clinical implications, Parkinsons Dis. 2012 (2012) 918719. https://doi.org/10.1155/2012/918719.

[60] M.Y. Osoba, A.K. Rao, S.K. Agrawal, A.K. Lalwani, Balance and gait in the elderly: A contemporary review, Laryngoscope Investig Otolaryngol. 4 (2019) 143-153. https://doi.org/10.1002/lio2.252.

[61] G. Vervoort, A. Bengevoord, E. Nackaerts, E. Heremans, W. Vandenberghe, A. Nieuwboer, Distal motor deficit contributions to postural instability and gait disorder in Parkinson's disease, Behav. Brain Res. 287 (2015) 1-7. https://doi.org/10.1016/j.bbr.2015.03.026. 
[62] N. Sempere-Rubio, J. López-Pascual, M. Aguilar-Rodríguez, S. Cortés-Amador, G. Espí-López, I. Villarrasa-Sapiña, P. Serra-Añó, Characterization of postural control impairment in women with fibromyalgia, PLoS ONE. 13 (2018) e0196575. https://doi.org/10.1371/journal.pone.0196575.

[63] L. Comber, J.J. Sosnoff, R. Galvin, S. Coote, Postural control deficits in people with Multiple Sclerosis: A systematic review and meta-analysis, Gait Posture. 61 (2018) 445-452. https://doi.org/10.1016/j.gaitpost.2018.02.018.

[64] S.M. Simmons, J.K. Caird, A. Ta, F. Sterzer, B.E. Hagel, Plight of the distracted pedestrian: a research synthesis and meta-analysis of mobile phone use on crossing behaviour, Inj Prev. 0 (2020) 1-7. https://doi.org/10.1136/injuryprev-2019-043426.

[65] I. Liu, R.M. Levy, J.J.S. Barton, G. laria, Age and gender differences in various topographical orientation strategies, Brain Res. 1410 (2011) 112-119. https://doi.org/10.1016/j.brainres.2011.07.005.

[66] D. Stavrinos, C.N. Pope, J. Shen, D.C. Schwebel, Distracted Walking, Bicycling, and Driving: Systematic Review and Meta-Analysis of Mobile Technology and Youth Crash Risk, Child Development. 89 (2018) 118-128. https://doi.org/10.1111/cdev.12827.

[67] J.D. Riley, V. Le, L. Der-Yeghiaian, J. See, J.M. Newton, N.S. Ward, S.C. Cramer, Anatomy of stroke injury predicts gains from therapy, Stroke. 42 (2011) 421-426. https://doi.org/10.1161/STROKEAHA.110.599340.

[68] N.J. Rosenblatt, M.D. Grabiner, Measures of frontal plane stability during treadmill and overground walking, Gait Posture. 31 (2010) 380-384. https://doi.org/10.1016/j.gaitpost.2010.01.002.

[69] J.R. Watt, J.R. Franz, K. Jackson, J. Dicharry, P.O. Riley, D.C. Kerrigan, A three-dimensional kinematic and kinetic comparison of overground and treadmill walking in healthy elderly subjects, Clin Biomech (Bristol, Avon). 25 (2010) 444-449. https://doi.org/10.1016/j.clinbiomech.2009.09.002.

[70] H. Nagano, R.K. Begg, W.A. Sparrow, S. Taylor, A comparison of treadmill and overground walking effects on step cycle asymmetry in young and older individuals, J Appl Biomech. 29 (2013) 188-193. https://doi.org/10.1123/jab.29.2.188.

[71] J.G. Wrightson, L. Schäfer, N.J. Smeeton, Dual-task prioritization during overground and treadmill walking in healthy adults, Gait Posture. 75 (2020) 109-114. https://doi.org/10.1016/j.gaitpost.2019.08.007.

[72] J.G. Wrightson, N.J. Smeeton, Walking modality, but not task difficulty, influences the control of dual-task walking, Gait Posture. 58 (2017) 136-138. https://doi.org/10.1016/j.gaitpost.2017.07.042.

[73] R. Penati, M. Schieppati, A. Nardone, Cognitive performance during gait is worsened by overground but enhanced by treadmill walking, Gait Posture. 76 (2020) 182-187. https://doi.org/10.1016/j.gaitpost.2019.12.006.

[74] T. Fujita, A. Sato, Y. Ohashi, K. Nishiyama, T. Ohashi, K. Yamane, Y. Yamamoto, K. Tsuchiya, K. Otsuki, F. Tozato, Amount of balance necessary for the independence of transfer and stairclimbing in stroke inpatients, Disabil Rehabil. 40 (2018) 1142-1145. https://doi.org/10.1080/09638288.2017.1289254.

[75] E. Desrosiers, C. Duclos, S. Nadeau, Gait adaptation during walking on an inclined pathway following spinal cord injury, Clin Biomech (Bristol, Avon). 29 (2014) 500-505. https://doi.org/10.1016/j.clinbiomech.2014.04.004.

[76] K. Smulders, R. van Swigchem, B.J.M. de Swart, A.C.H. Geurts, V. Weerdesteyn, Communitydwelling people with chronic stroke need disproportionate attention while walking and negotiating obstacles, Gait Posture. 36 (2012) 127-132. https://doi.org/10.1016/j.gaitpost.2012.02.002.

[77] V. Miyasike-daSilva, J.C. Singer, W.E. Mcllroy, A role for the lower visual field information in stair climbing, Gait Posture. 70 (2019) 162-167. https://doi.org/10.1016/j.gaitpost.2019.02.033. 


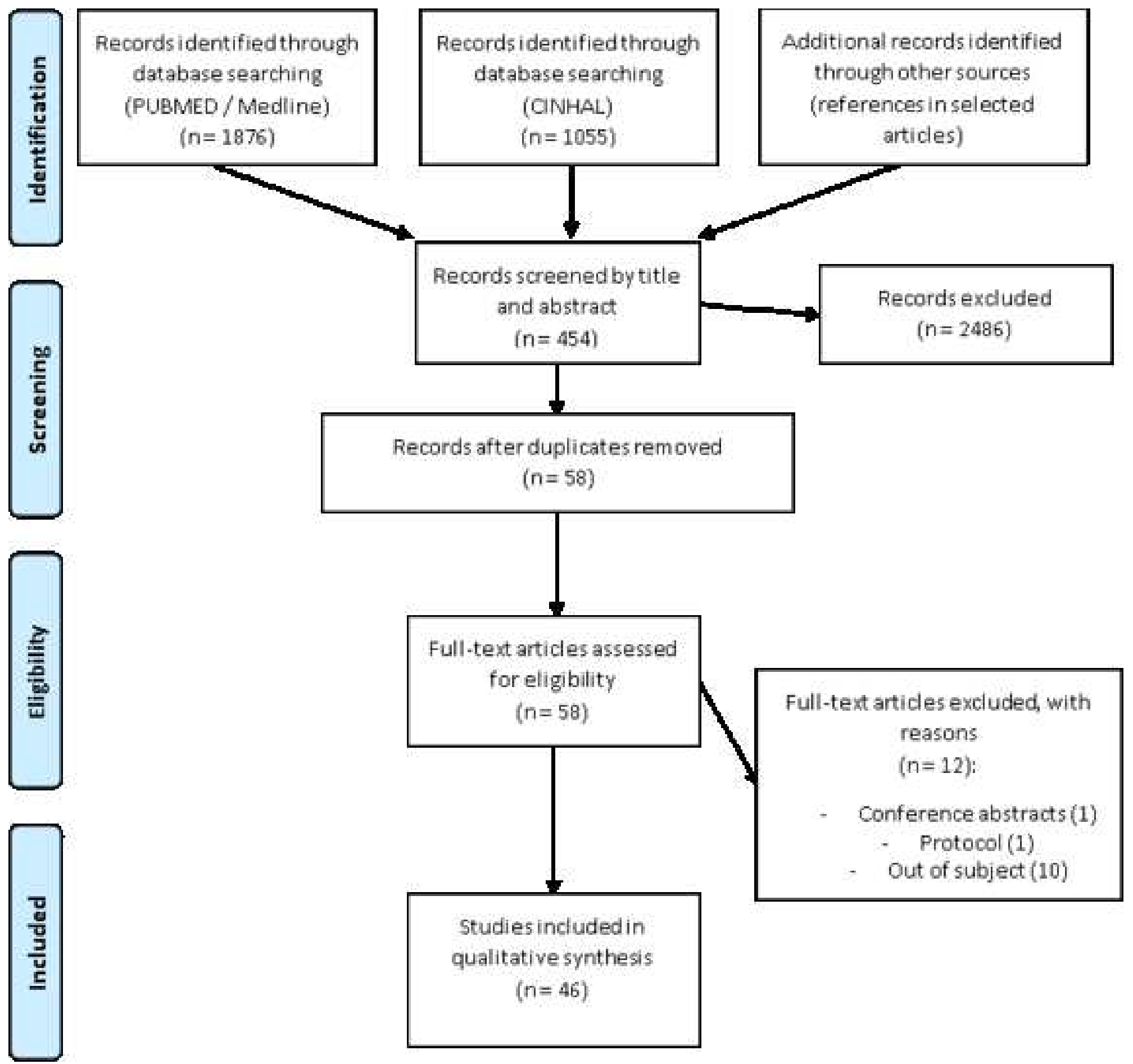




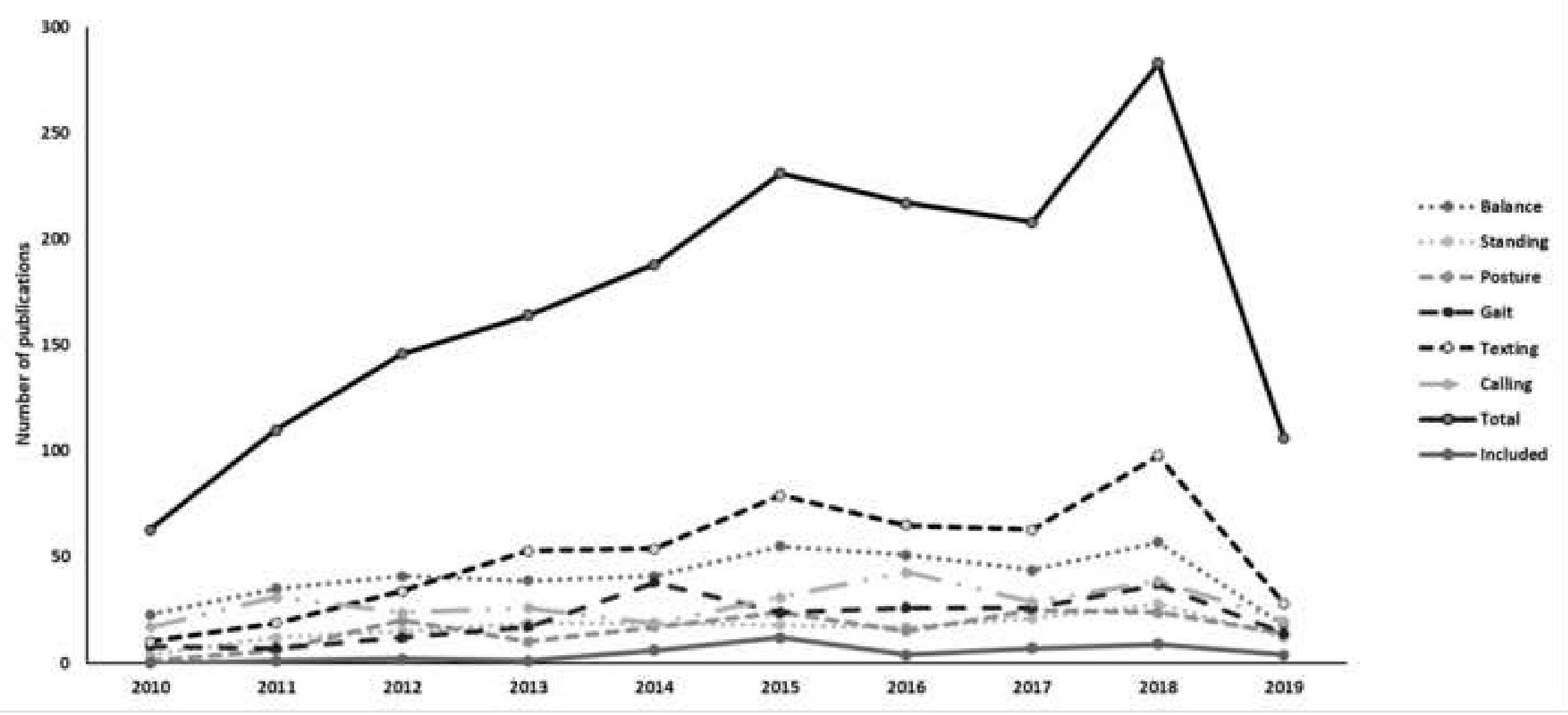


Figure_3

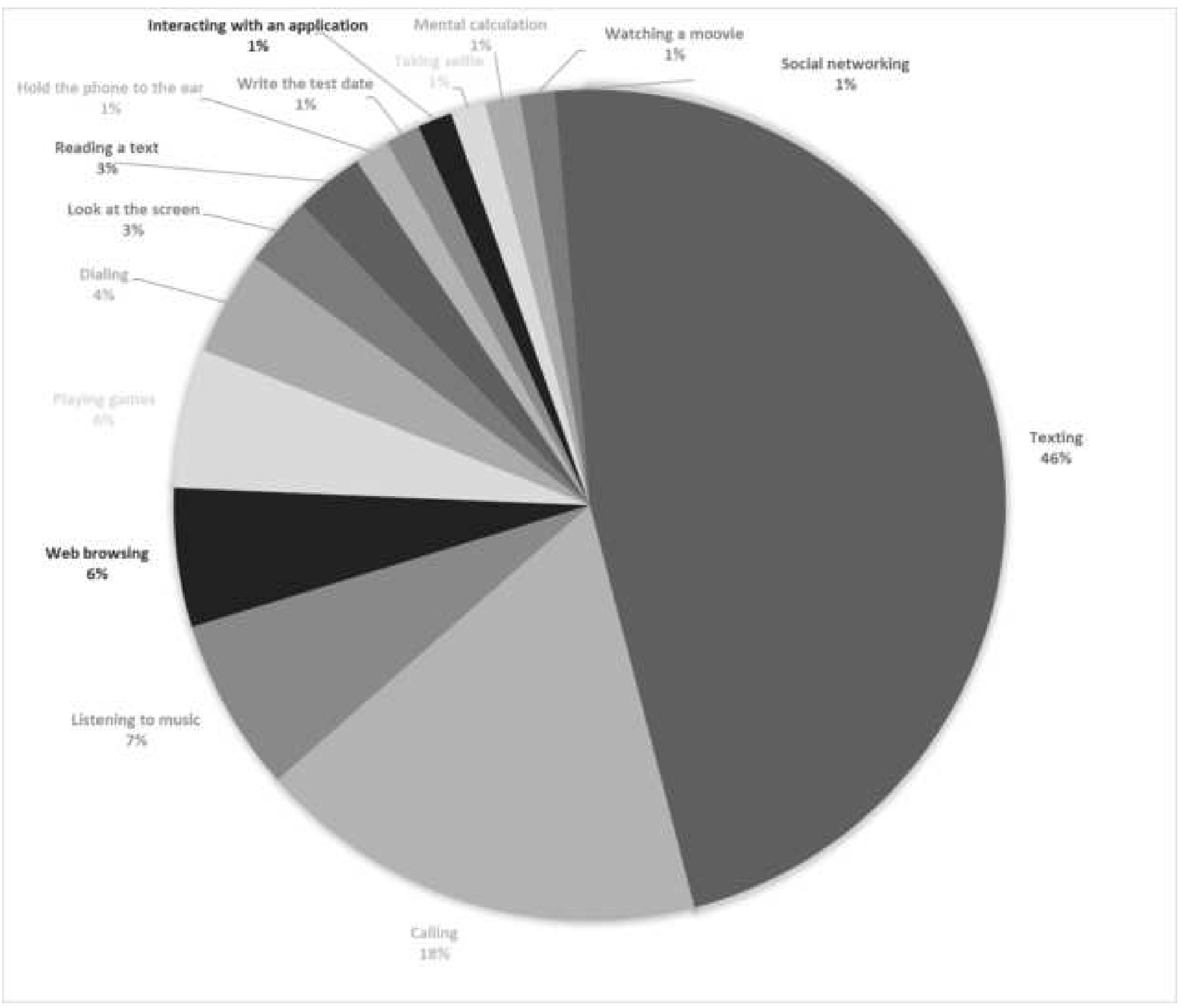




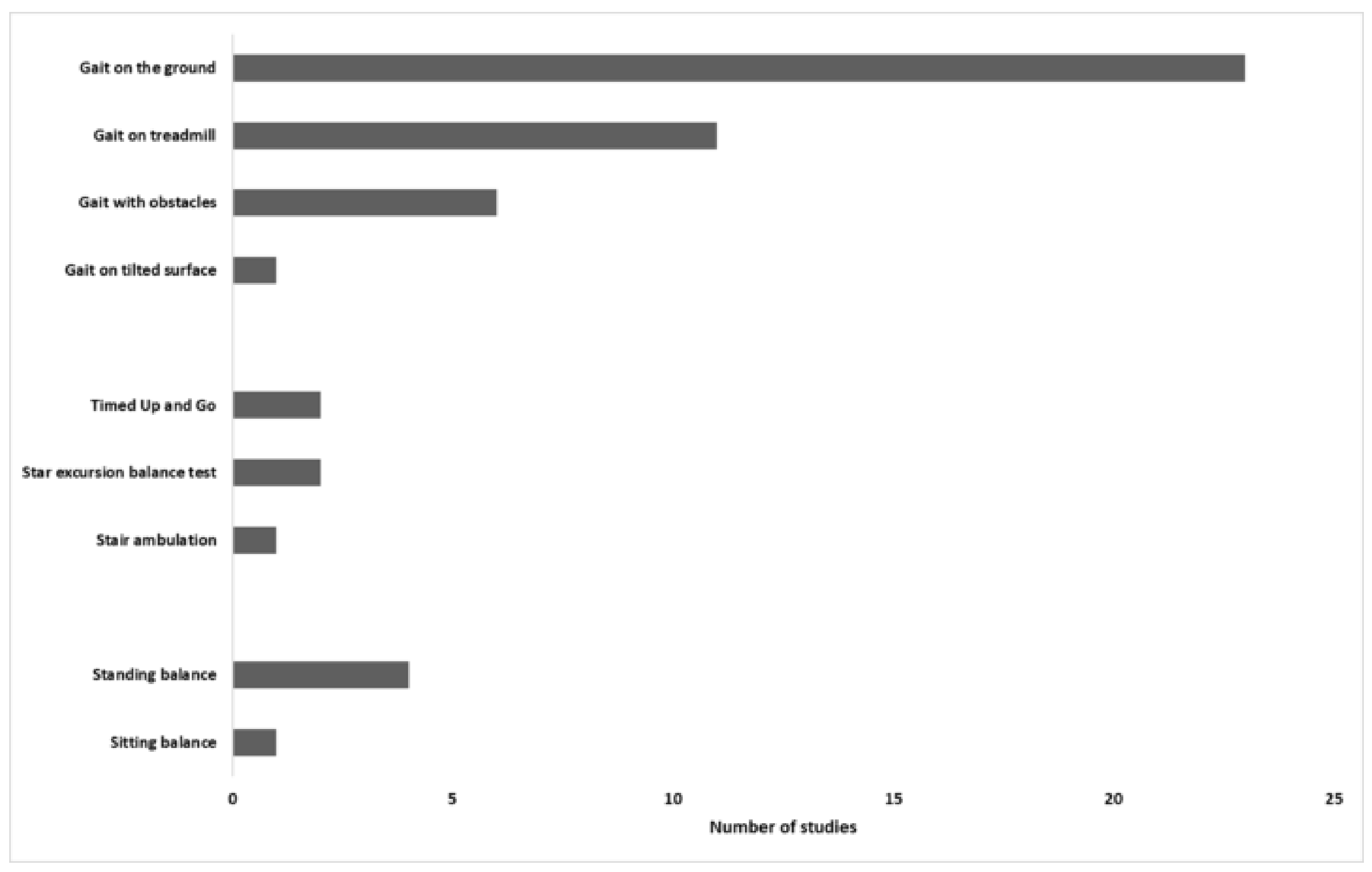


Table 1: Geography, method, setting and population information of included studies.

\begin{tabular}{|c|c|c|}
\hline Item & Variables & Percentage \\
\hline \multirow[t]{6}{*}{ Localisation } & North America & $24 / 46$ \\
\hline & Asia & $12 / 46$ \\
\hline & Europa & $7 / 46$ \\
\hline & Africa & $1 / 46$ \\
\hline & South America & $1 / 46$ \\
\hline & Australia-Oceania & $1 / 46$ \\
\hline \multirow[t]{2}{*}{ Method } & $\begin{array}{l}\text { Observational study } \\
\text { (comparison between } \\
\text { condition) }\end{array}$ & $36 / 46$ \\
\hline & $\begin{array}{l}\text { Observational study } \\
\text { (comparison between } \\
\text { conditions and groups) }\end{array}$ & $10 / 46$ \\
\hline \multirow[t]{3}{*}{ Setting } & Laboratory & $35 / 46$ \\
\hline & $\begin{array}{l}\text { Street or outside (ecological } \\
\text { condition) }\end{array}$ & $9 / 46$ \\
\hline & Clinical & $4 / 46$ \\
\hline \multirow[t]{5}{*}{ Population } & Healthy subjects & $45 / 46$ \\
\hline & Including older subjects & $6 / 46$ \\
\hline & Multiple sclerosis & $2 / 46$ \\
\hline & Fibromyalgia & $1 / 46$ \\
\hline & Parkinson & $1 / 46$ \\
\hline \multirow[t]{6}{*}{ Number of subjects } & $<10$ & $7 / 46$ \\
\hline & $10-20$ & $14 / 46$ \\
\hline & $21-50$ & $22 / 46$ \\
\hline & $50-100$ & $1 / 46$ \\
\hline & $100-500$ & $0 / 46$ \\
\hline & $>500$ & $2 / 46$ \\
\hline
\end{tabular}


Table 2 : Key results of the effect of using a smartphone during different posturo-locomotor tasks. The number of studies reporting the observation is indicated in parenthesis, when required.

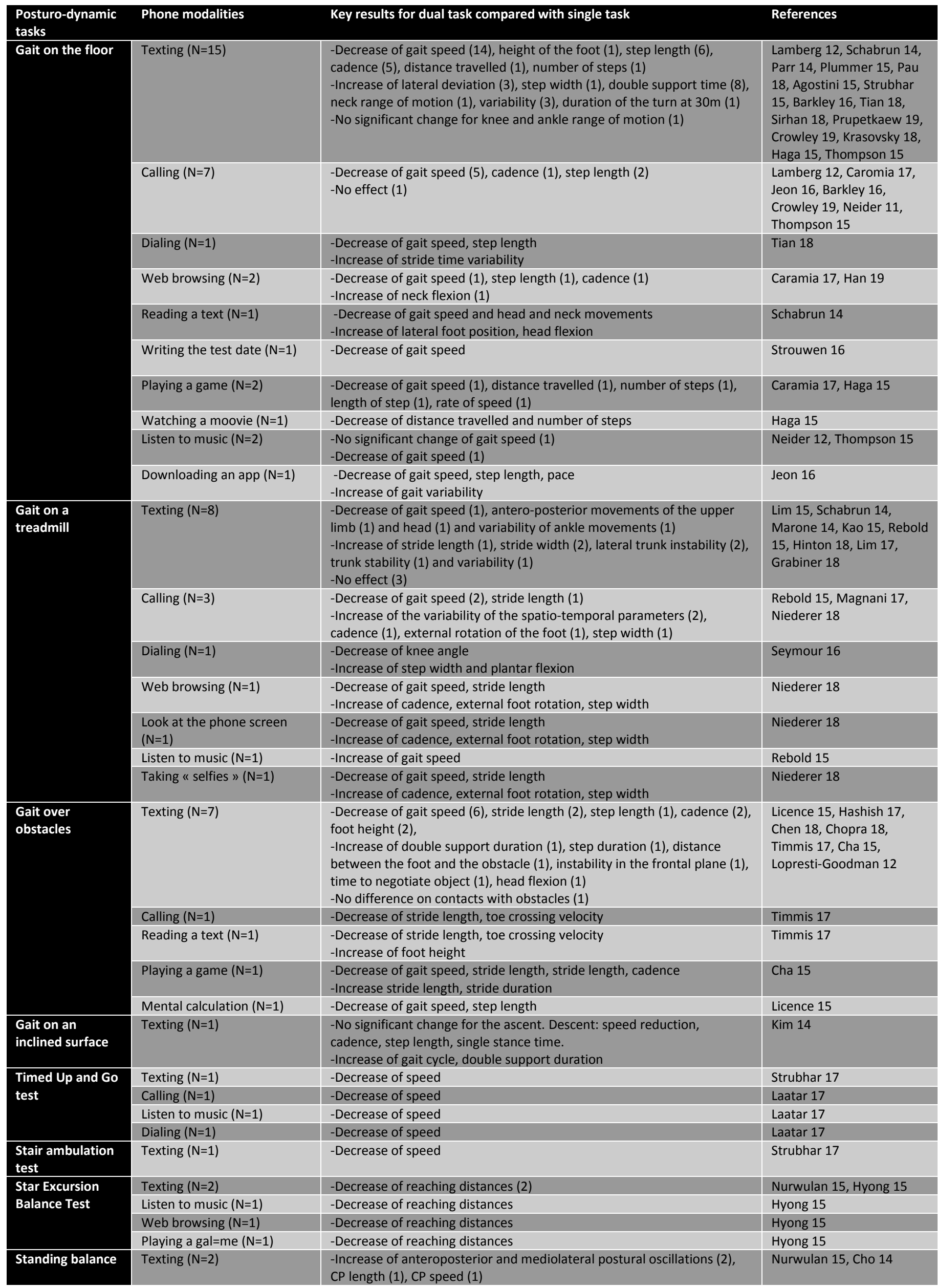



displacement

Interacting on social network -Increase of CoP surface, antero-posterior and medio-lateral displacement (1)

Increase of antero-posterior and medio-lateral postural oscillations

Cho 14

\section{-No effect}


Conflict of interest: none.

Funding: This research did not receive any specific grant from funding agencies in the public, commercial, or not-for-profit sectors.

\section{Author contributions:}

ND: conceptualization; investigation; methodology; review process; data analysis and interpretation; writing original draft; final approval of the version to be submitted.

AVB: conceptualization; investigation; methodology; review process; data analysis and interpretation; writing original draft; final approval of the version to be submitted. 